\title{
Comparative Floral Characters, Pollinator Limitation, and Pollination Success in Different Habitats of Caragana microphylla Lam
}

\author{
Min Chen ${ }^{1,2,3 *}$, Xiao-an Zuo ${ }^{1,2}$ and Xue-yong Zhao ${ }^{1,2 *}$ \\ ${ }^{1}$ Northwest Institute of Eco-Environment and Resources, Chinese Academy of Sciences, Lanzhou, China, ${ }^{2}$ Urat \\ Desert-Grassland Research Station, Northwest Institute of Eco-Environment and Resources, Chinese Academy of Sciences, \\ Lanzhou, China, ${ }^{3}$ Naiman Desertification Research Station, Northwest Institute of Eco-Environment and Resources, Chinese \\ Academy of Sciences, Lanzhou, China
}

\section{OPEN ACCESS}

Edited by:

Janet Prevey,

United States Geological Survey (USGS), United States

Reviewed by:

Gao Chen,

Chinese Academy of Sciences, China

Felipe Yon,

Universidad Peruana Cayetano

Heredia, Peru

*Correspondence:

Min Chen

chenmin1360@126.com

Xue-yong Zhao

zhaoxy@/zb.ac.cn

Specialty section:

This article was submitted to Behavioral and Evolutionary Ecology,

a section of the journal

Frontiers in Ecology and Evolution

Received: 04 November 2019

Accepted: 14 May 2020

Published: 10 June 2020

Citation:

Chen M, Zuo X and Zhao X (2020) Comparative Floral Characters,

Pollinator Limitation, and Pollination

Success in Different Habitats of

Caragana microphylla Lam.

Front. Ecol. Evol. 8:170.

doi: 10.3389/fevo.2020.00170
Caragana microphylla Lam plays an important role in desert-grassland revegetation. Plant reproduction in arid regions may be restricted due to the low abundance or visiting frequency of pollinators. We tested the visited flowers, the pollinated flowers and seed production to estimate how pollinator limitation affects the seed numbers of visited and pollinated flowers. We investigated the floral characters, pollinator activities, and breeding systems of C. microphylla. Our results showed that pollinator limitation was the dominant limiting factor in seed production. In addition, floral characters were moderately positively correlated, and more open flowers with large corollas and long spurs were observed in the natural plots than in grazed plots. Apis mellifera was the most important pollinator. Our findings further indicate that the number of opening flowers and rate of pollinator visitation were positively correlated. In C. microphylla, insect pollination was dominant in outcrossing, and self-pollination played a supporting role in ensuring successful pollination. This study provides a better understanding of how grazing habitat affects floral characters, pollinator limitation, and pollination success of $C$. microphylla.

Keywords: floral characters, pollinator limitation, insect visitation rate, pollinator, seed production

\section{INTRODUCTION}

In flowering plants, pollination success can be affected by the floral characters, pollinators, and breeding systems (Ashman and Morgan, 2004; Ashman et al., 2004). Reports have indicated that measures of pollination success are related to floral traits in flowering plants. For example, insect pollination success is positively related to the plant height, number of flowers, and spur length in Disa draconis (Johnson and Steiner, 1997; Johnson and Nilsson, 1999; Sun et al., 2009). Pollination is an important stage in plant reproduction, and plant-pollinator interactions are considered a key process (Stebbins, 1970; Kevan et al., 1990; Gómez et al., 2007). The number of open flowers could influence attractiveness to pollinators, and the importance of the plant stature for pollination success could depend on the vegetation height (Grindeland et al., 2005; Toräng et al., 2006). Many insect-pollinated plants have evolved floral characters that efficiently attract a single pollinator species, and efficient pollinators also adapt to better exploit the selection on floral attractants and resources (Johnson and Steiner, 2000; Gómez et al., 2007). Over the past two decades, many plant species relying on less effective pollinators (transfer less pollen) have been shown to present significant decreases in the seed number per flower (Burd, 1994; Michael et al., 2003). 
Pollinator limitation is an important constraint on the reproduction of flowering plants (Bierzychudek, 1981; Suzuki, 2000). A plant's pollination success can be reduced by inadequate pollinators or an insufficient pollen supply, which is called the "pollinator limitation" (Bierzychudek, 1981). Suzuki (2000) suggested that plants provide more resources (nectar, pollen, and anthers) to pollinators, and the pollinator transfers pollen while collecting the offered reward in flowering plants. In addition, floral characters and anthers attract pollinators to specific flowers and nectar and pollen are the major targets of pollinators (Ortíz et al., 2010). Pollinator limitation seems to be associated with a decreased abundance and diversity of insects (Gómez et al., 2010; Alberto and Fernando, 2014). Nayak and Davidar (2010) indicated that pollinator limitation was primarily due to scarce or ineffective pollinators, which may correspond to low amounts of pollen grains per visit.

Many flowering plants often suffer from pollinator limitation, which may lead to low reproductive output (Bierzychudek, 1981; Asikainen and Mutikainen, 2005). The impacts of humans and grazing on landscapes result in altered habitats and can negatively influence pollinator activity (Rodríguez-Cabal et al., 2007). Changes in habitats causing increases or decreases in plant density may consequently influence pollinator activity and plant pollination success (Hadley and Betts, 2012). Many plant species relying on less effective pollinators may be subject to significant decreases in pollination success if pollinator activity and numbers are influenced by management activities and altered habitats (Allen-Wardell et al., 1998; Michael et al., 2003). Furthermore, the reduction of pollinators disrupts plant pollination processes, thus contributing to the decline of seed production (Cresswell, 1997; Robertson et al., 1999; Ashman et al., 2004; Melissa et al., 2015).

The aims of the present study were to (1) detect the possible differences in floral characters and pollinator activity between natural and grazing habitats; (2) determine how pollinator limitation affects pollination success based on the proportion of visited flowers, pollinated flowers, and seed production; and (3) evaluate the correlation between pollinator visitation frequency and open flower number in both habitats. In addition, we assessed the relationships between pollinator activity and breeding systems.

\section{MATERIALS AND METHODS}

\section{Plant Species}

C. microphylla (Leguminosae: Caragana) is a shrub that usually ranges from 0.4 to $1.8 \mathrm{~m}$ in height and occurs in the provinces of Gansu and western Inner Mongolia. The root system of $C$. microphylla is well-developed and drought resistant. This species has spine-like stipules that are usually $1.5-5 \mathrm{~mm}$. The corolla is yellow and $2.5 \mathrm{~cm}$ in height.

\section{Study Area and Experimental Design}

The study site is located in the Urat Desert grassland to the west of Inner Mongolia $\left(41^{\circ} 06^{\prime}-41^{\circ} 25^{\prime} \mathrm{N}\right.$ and $\left.106^{\circ} 59^{\prime}-107^{\circ} 05^{\prime} \mathrm{E}\right)$. This study was carried out from April 2016 to September 2018.
The average annual temperature is $3.8^{\circ} \mathrm{C}$, and the average annual rainfall is $\sim 162.0-178.6 \mathrm{~mm}$.

This experiment involved two habitats with six natural plots and six grazing plots of $20 \times 20 \mathrm{~m}$ each. In the natural habitat, C. microphylla is the dominant species without artificial management, and Salsola passerina Bunge is the accompanying species in natural patches. In grazing habitat, Stipa glareosa P. Smirn is the accompanying species. In both habitats, the average plant density of C. microphylla was 15 individuals per $100 \mathrm{~m}^{2}$ (Figure 1).

\section{Effect of Grazing on Vegetation}

We designed a natural habitat and a grazing habitat (six plots per habitat). In the natural habitat, $C$. microphylla was the dominant species and the plots were protected from livestock grazing. The grazing experiments were performed from 2016 to 2018, according to the moderate grazing intensity ( 0.25 sheep per ha) in Inner Mongolia steppe (Chen and Zhao, 2019). In addition, the grazing period was from May to August (08:00 to 19:00 daily). In September, we recorded and counted the vegetation cover (VC), vegetation density (VD), vegetation height $(\mathrm{VH})$, and aboveground plant biomass (AGB) of C. microphylla in the studied habitats.

\section{Floral Characters and Phenotypic Selection}

To assess the floral characters in the different habitats, we randomly selected 24 plants and observed the plant heights, flower numbers, corolla sizes, and spur lengths in each habitat. In the flowering period, we measured the plant height (the distance from the topmost flower to the ground) of each selected plant. In three labeled inflorescences of each selected plant, we also measured the spur length (the distance from the corolla to the spur tip) and the corolla size (the product of width and height) with digital calipers (Sletvold et al., 2010). In addition, we recorded the number of open flowers in the selected plants.

\section{Pollinator Limitation}

In the studied habitats, in total, we selected 18 plants in the natural plots and 18 individuals in the grazing plots (three plants per plot). In each plant, 15 flowering buds were marked with tags. We used the HD camera (SONY HXR-MC2500, the resolution is $1920 \times 1080)$ to note the progression of the flowering stages and observe anthesis in the marked flowers. The HD camera was used to record pollinators collecting nectar and pollen in visiting duration. The time-lapse camera was used to record video over $12 \mathrm{~h}$ in each observed day. Effective pollination was recorded when the pollinators collected and delivered pollen to the stigmas.

To determine whether pollinator limitation affected the pollination success, we counted the sequence of flower opening, pollinator visitation, and seed production from May to September after all seeds had matured. The flowers of $C$. microphylla evolved a tripping mechanism, and the pollinator acts as a tripping agent. In addition, a pollinator visit was defined as a pollinator landing on the flowers. Effective pollination was recorded when the pollinators collected or transferred pollen. 

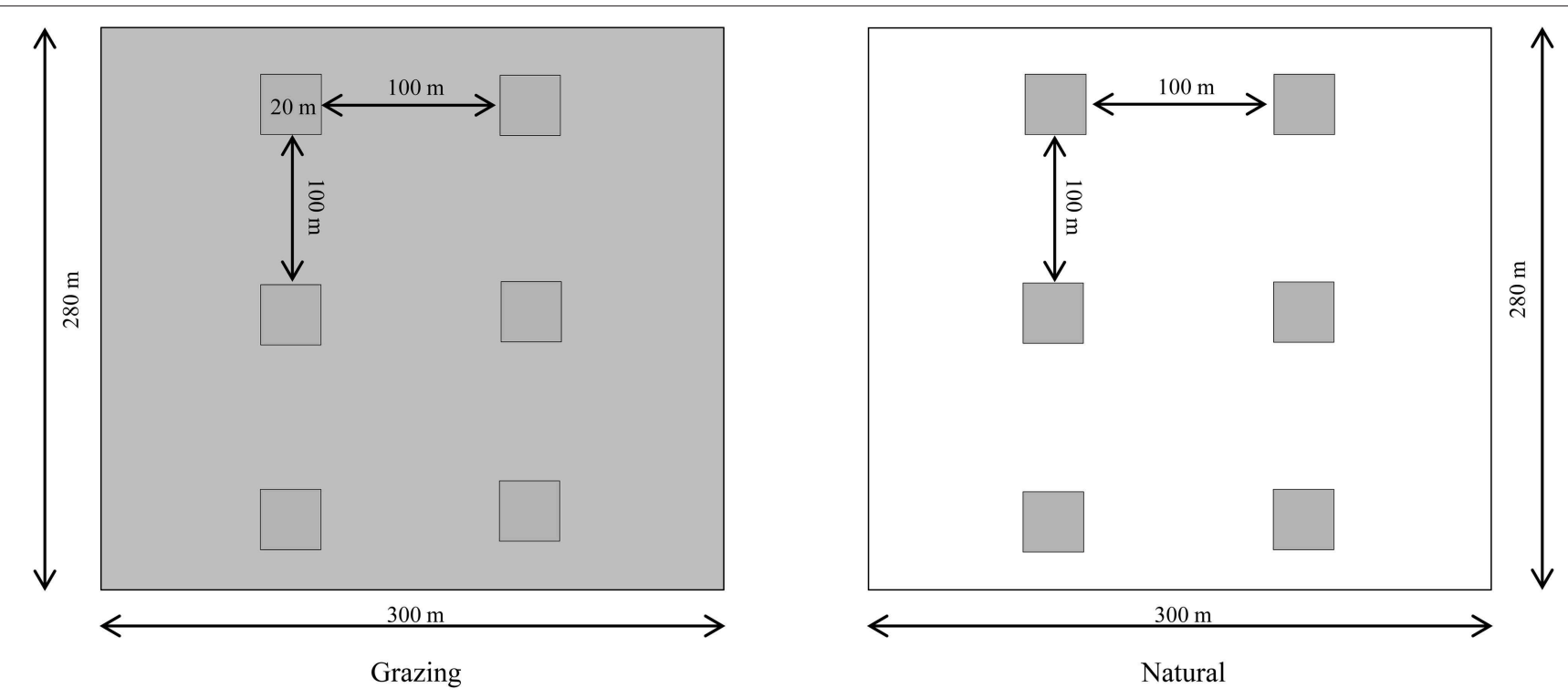

FIGURE 1 | Experimental design of the natural and grazing habitats (six plots per habitat) from 2016 to 2018 . In the grazing habitat, grazing experiments were performed (white area). The natural plots were surrounded by undisturbed vegetation (gray area). In each plot $(20 \times 20 \mathrm{~m})$, the average density of $C$. microphylla was 15 individuals per $100 \mathrm{~m}^{2}$, and the two habitats were separated by $1,000 \mathrm{~m}$.

We recorded the number of visited flowers and pollinated flowers and counted the seed production per flower once the flowers produced at least one seed. In September, the following equations were used to calculate the impact of management on the percentage of seeds among the visited flowers and pollinated flowers (Suzuki, 2000; Chen and Zhao, 2017):

$$
\begin{gathered}
\text { Percentage of pollinated among visited flowers }=\frac{P}{V} \times 100 \% \\
\text { Percentage of seeds among visited flowers }=\frac{S}{V} \times 100 \% \\
\text { Percentage of seeds among pollinated flowers }=\frac{S}{P} \times 100 \%
\end{gathered}
$$

Where $\mathrm{V}$ is the number of visited flowers, $\mathrm{P}$ is the number of pollinated flowers, and $\mathrm{S}$ is the seed production of flowers in the marked plants.

\section{Pollinator Visitation and Activity}

To investigate pollinator visitation in the different habitats, the identity and quantity were measured. The marked flowers were observed daily between 07:00 and 19:00. The pollinators were randomly captured using insect nets in each plot, and the presence or absence of pollen grains adhering to their bodies was determined in the laboratory using a stereomicroscope. In addition, pollen preparations were made by rubbing a cube of fuchsin-stained jelly over the pollinator body (Beattie, 1971). The presence of pollen was regarded as proof of flower visitation. In flowering period, we randomly selected three plants in each plot to determine the identity and surveys of pollinators. We performed $12 \mathrm{~h}$ focal observations from $06: 00$ to $18: 00$ in each day. We used $\mathrm{HD}$ camera to record the duration of each pollinator visit, the time until some of them visited the plot, and the number of plants and number of flowers visited per foraging bout. In each habitat, six surveyors used $84 \mathrm{~h}$ ( $12 \mathrm{~h}$ per day) to record pollinator activity because each observation period was 1 week. The following equation was used to calculate the visiting frequency of the pollinators (Goverde et al., 2002; Chen and Zuo, 2019):

$$
\text { Visitation frequency }=\frac{N V}{N F^{*} T},
$$

where $\mathrm{N}_{\mathrm{V}}$ is the number of pollinator visits, $\mathrm{N}_{\mathrm{F}}$ is the number of marked flowers, and $\mathrm{T}$ is the observation time of the pollinator visits.

\section{Pollination Experiments of the Affected Seed Set}

To identify the pollination success of $C$. microphylla, we counted seed production in the different experiments. In total, 864 flowers were collected across the 12 plots, where there were three plants per plot, four branches per marked plant, and six marked flowers per branch. On the same marked plant, we selected one branch for natural pollination and the other branch for manual crosspollination, where the sampled flowers (emasculation) received pollen from other plants (Krishnana et al., 2012).

On the same marked plant, we selected one branch for wind pollination and the remaining branch for self-pollination. In the wind-pollinated treatment, we used fine mesh $\left(1 \mathrm{~mm}^{2}\right)$ to prevent insect visitation and the stamens were removed. In the selfpollination treatment, the marked flowers accepted pollen from the same flowers and we used paper bags to cover the flowers to exclude pollinating agents. In September, we counted the seed production from these marked flowers within 2 months in these 
treatments. The following equation was used to calculate the selfcompatibility index (SCI) (Zapata and Arroyo, 1978; Chen et al., 2019):

$$
\text { Self - compatibility index }=\frac{S S}{S m},
$$

where $S_{s}$ is the seed set of self-pollination, and $S_{m}$ is the seed set of manual cross-pollination. SCI values $>0.2$ indicate selfcompatibility, and values $\leq 0.2$ indicate self-incompatibility.

\section{Data Analyses}

A generalized linear model (GLM) was used to determine the effects of the pollination treatments, different habitats (natural and grazing), and years (from 2016 to 2018) on the seed set. A gamma distribution and a logit link function were performed. In the model, the pollination treatments, different habitats, and years were used as the fixed factors, and the mean seed set represented the dependent variable. The likelihood ratio test was applied to the model, and treatment differences were assessed to determine significance via Tukey's multiple comparisons.

Analysis of variance (ANOVA) was used to compare the traits of the flowers (plant height, average number of open flowers, corolla size and spur length) in both populations. Regression analyses were performed using SPSS 21.0. In this model, regression analyses were performed using the percentages of visited flowers and pollinated flowers as the independent variable and the percentages of seeds as the dependent variable.

\section{RESULTS}

\section{Effect of Grazing on Vegetation}

In the studied habitats, the vegetation cover (VC), vegetation density (VD), vegetation height (VH), and aboveground plant biomass (AGB) of C. microphylla are shown in Figure 2. Our findings demonstrated that the plants in the natural plots possess a higher $\mathrm{VD}, \mathrm{VH}$, and $\mathrm{AGB}$ than those in the grazing plots $(d f=$ $1, P<0.05)$. However, there was no difference in the VC between the studied patches $(d f=1, P>0.05)$.

\section{Floral Characters and Phenotypic Selection}

The plant heights, number of opened flowers, corolla sizes, and spur lengths in the natural and grazing habitats are shown in Table 1. Our results indicated that the corolla size and spur length were not significantly different between the habitats. We observed that the plant height was (mean number \pm SD) $180.2 \pm$ 11.7 in the natural habitat and $160.9 \pm 10.6$ in the grazing habitat. In addition, our results indicated that the average number of open flowers in the natural and grazing habitats was $15.1 \pm 2.0$ and 11.3 \pm 1.2 , respectively. The plant height and number of open flowers of the natural plants were significantly higher than those of the grazing plants (Table $\mathbf{1}$ ).

Moreover, these outcomes showed that the floral characters were moderately positively correlated and the natural plants

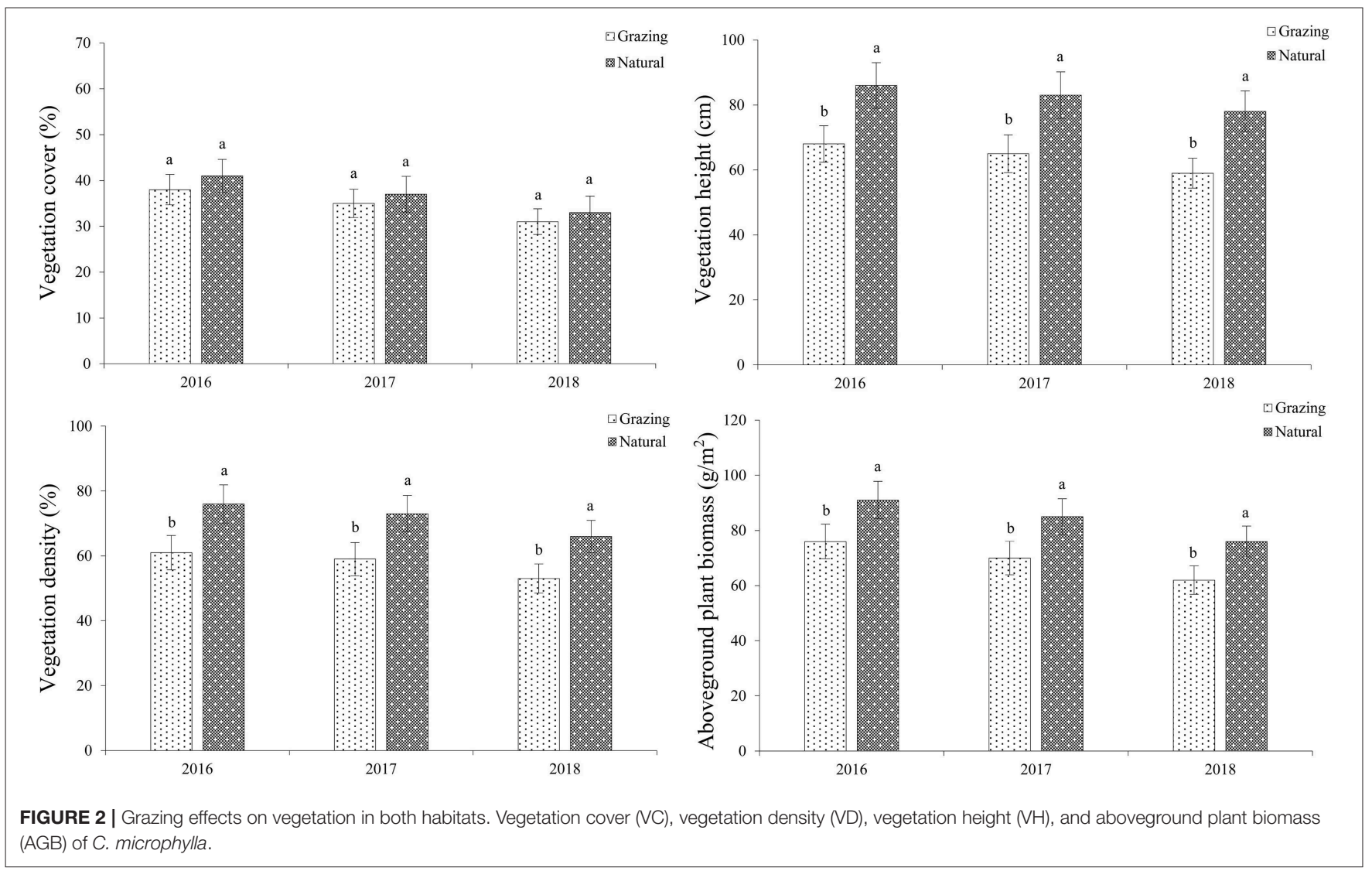


tended to have more open flowers with large corollas and long spurs (Table 2).

\section{Pollinator Limitation}

Our results indicated that $65.7 \pm 1.4 \%$ of the flowers $(n=$ 270 , Mean \pm SD) were visited $(V)$ and that $53.1 \pm 1.2 \%$ of the

TABLE 1 | Floral traits (mean \pm SD) of the grazing plants and natural plants in C. microphylla.

\begin{tabular}{lccc}
\hline Traits & Grazing & Natural & $\boldsymbol{P}$ \\
\hline Plant height $(\mathrm{cm})$ & $160.9 \pm 10.6$ & $180.2 \pm 11.7$ & $P<0.05$ \\
Number of open flowers & $11.3 \pm 1.2$ & $15.1 \pm 2.0$ & $P<0.05$ \\
Spur length $(\mathrm{mm})$ & $12.7 \pm 1.4$ & $14.9 \pm 2.8$ & $P>0.05$ \\
Corolla size $\left(\mathrm{mm}^{2}\right)$ & $199.6 \pm 10.6$ & $204.4 \pm 13.9$ & $P>0.05$ \\
\hline
\end{tabular}

TABLE 2 | Phenotypic correlations among the traits of C. microphylla based on the grazing plants (above the diagonal) and natural plants (below the diagonal).

\begin{tabular}{lclcc}
\hline & Plant height & $\begin{array}{l}\text { Number of } \\
\text { opening flowers }\end{array}$ & Spur length & Corolla size \\
\hline $\begin{array}{l}\text { Plant height } \\
\text { Number of }\end{array}$ & $0.665^{\star \star}$ & $0.884^{\star \star}$ & $0.890^{\star \star}$ & $0.863^{\star \star}$ \\
open flowers & & & $0.748^{\star \star}$ & $0.894^{\star \star}$ \\
$\begin{array}{l}\text { Corolla size } \\
\text { Spur length }\end{array}$ & $0.535^{\star \star}$ & $0.603^{\star \star}$ & & $0.705^{\star \star}$ \\
& $0.805^{\star \star}$ & $0.761^{\star \star}$ & $0.610^{\star \star}$ & \\
\hline
\end{tabular}

${ }^{* *} P<0.01$ flowers were pollinated $(\mathrm{P})$ in the grazing plants; therefore, the percentage of pollinated flowers among the visited flowers $(\mathrm{P} / \mathrm{V}$ $\times 100 \%$ ) was $80.8 \%$ (Figure 3 ). In addition, $29.2 \pm 2.7 \%$ of the flowers produced seeds $(\mathrm{S})$; therefore, the percentage of seeds among the visited flowers $(\mathrm{S} / \mathrm{V} \times 100 \%)$ and pollinated flowers $(\mathrm{S} / \mathrm{P} \times 100 \%)$ was 44.4 and $55.0 \%$, respectively, in the grazing plants. In the natural plants, $78.7 \pm 1.2 \%$ of the flowers were visited $(\mathrm{V}), 65.3 \pm 2.7 \%$ of flowers were pollinated $(\mathrm{P})$, and $43.2 \pm$ $1.6 \%$ of the flowers produced seeds $(\mathrm{S})$. Therefore, the percentage of pollinated flowers among the visited flowers $(\mathrm{P} / \mathrm{V} \times 100 \%)$ was $83.0 \%$. In addition, the percentage of seeds among the visited flowers $(\mathrm{S} / \mathrm{V} \times 100 \%)$ and pollinated flowers $(\mathrm{S} / \mathrm{P} \times 100 \%)$ were $54.9 \pm 3.6$ and $66.2 \pm 5.2 \%$, respectively, in the natural habitat.

Our results showed that there was a positive correlation between the insect visitation rates and the number of seeds of the visited flowers in both habitats, clearly suggesting that a higher seed production occurred in the plant with the higher insect visitation rate (grazing, $r=0.78, P<0.01$; natural, $r=0.79, P$ $<0.01$; Figure 4). In addition, the visited flowers of the natural plants had a higher seed production than the grazing plants because of the higher insect visitation rate in the natural plants.

\section{Pollinator Visitation and Activity}

In the studied plots, 286 pollinator visits were observed, and Apis mellifera accounted for $52.6 \%$ of all visits. The other occasional visitors included Megachile manchuriana Yasumatsu, Episyrphus balteatus, Bombus lucorum, and Pieris rapae (Linnaeus); however, these species only played an assistant role in pollination visits

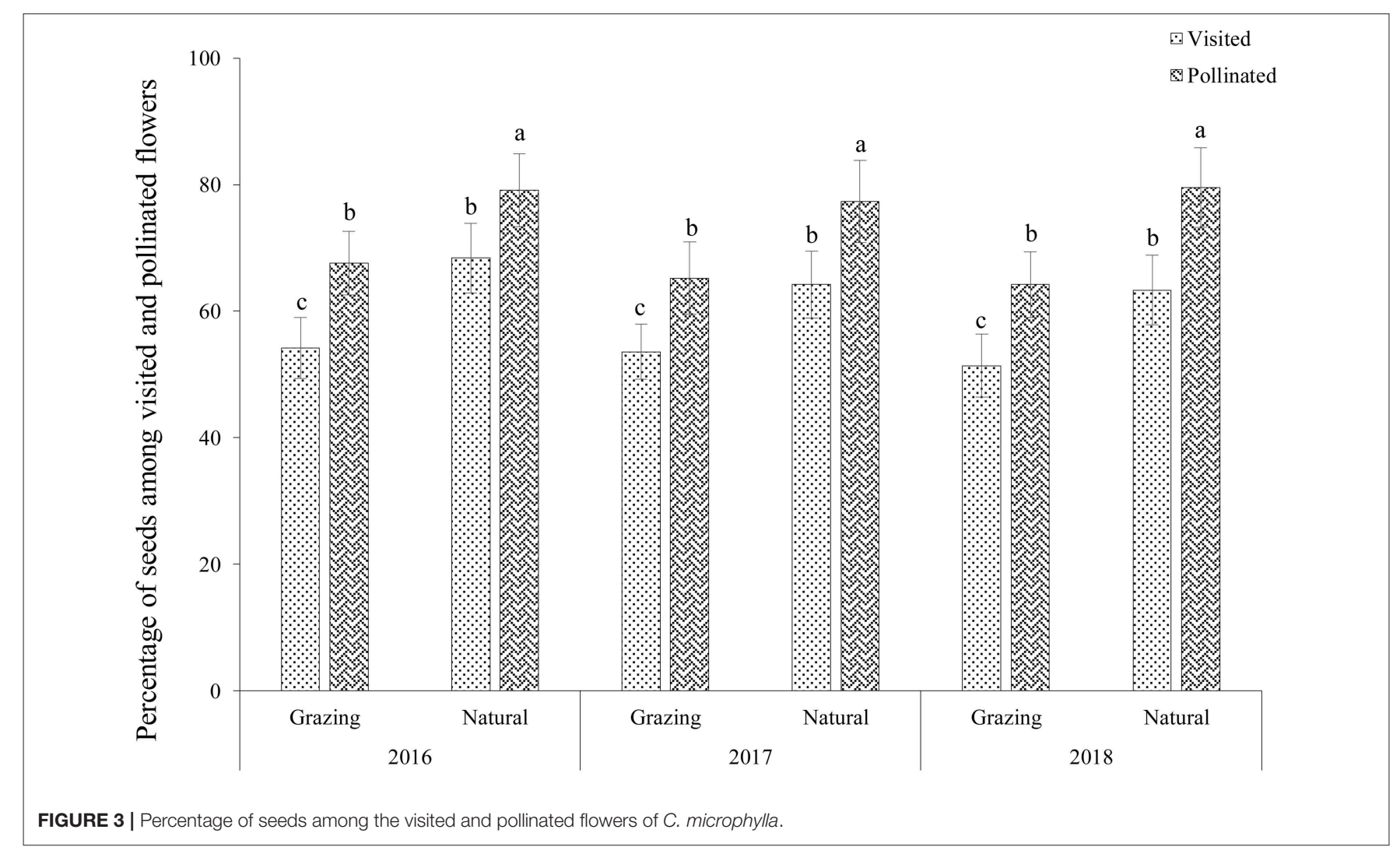




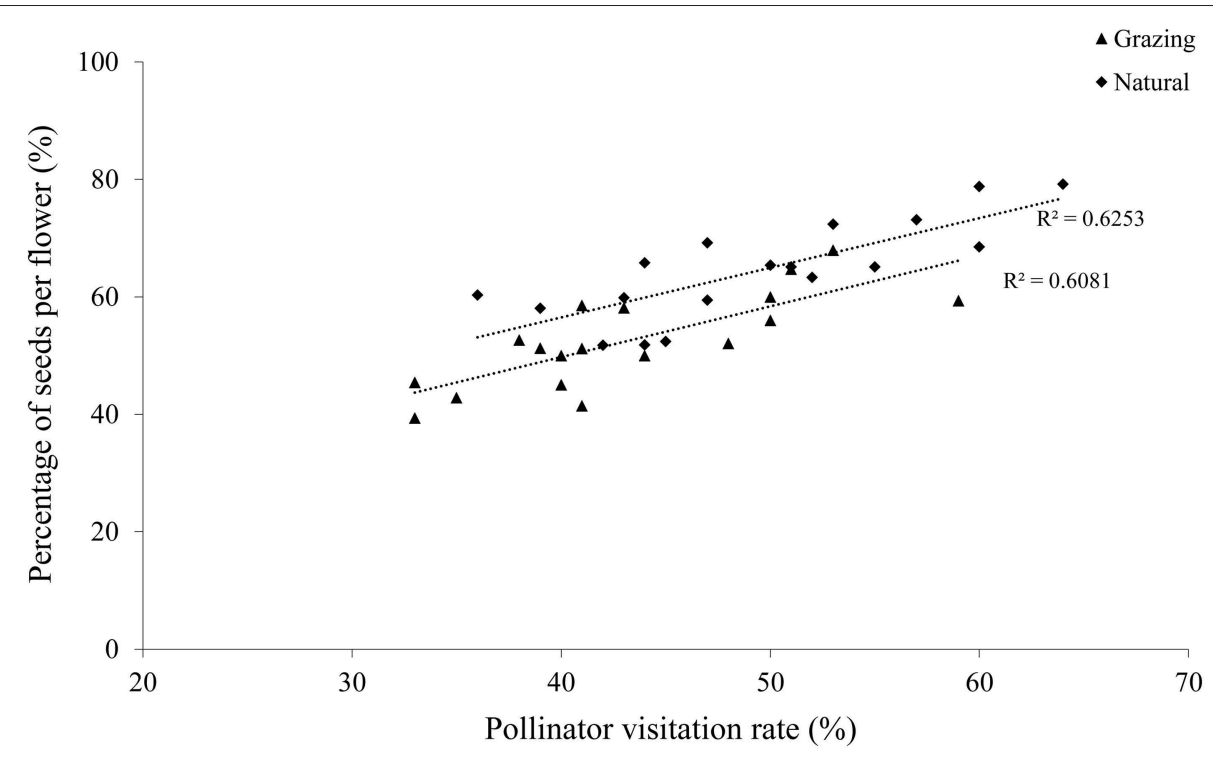

FIGURE 4 | Relationship between the proportion of seeds per flower and the pollinator visitation rate of C. microphylla.

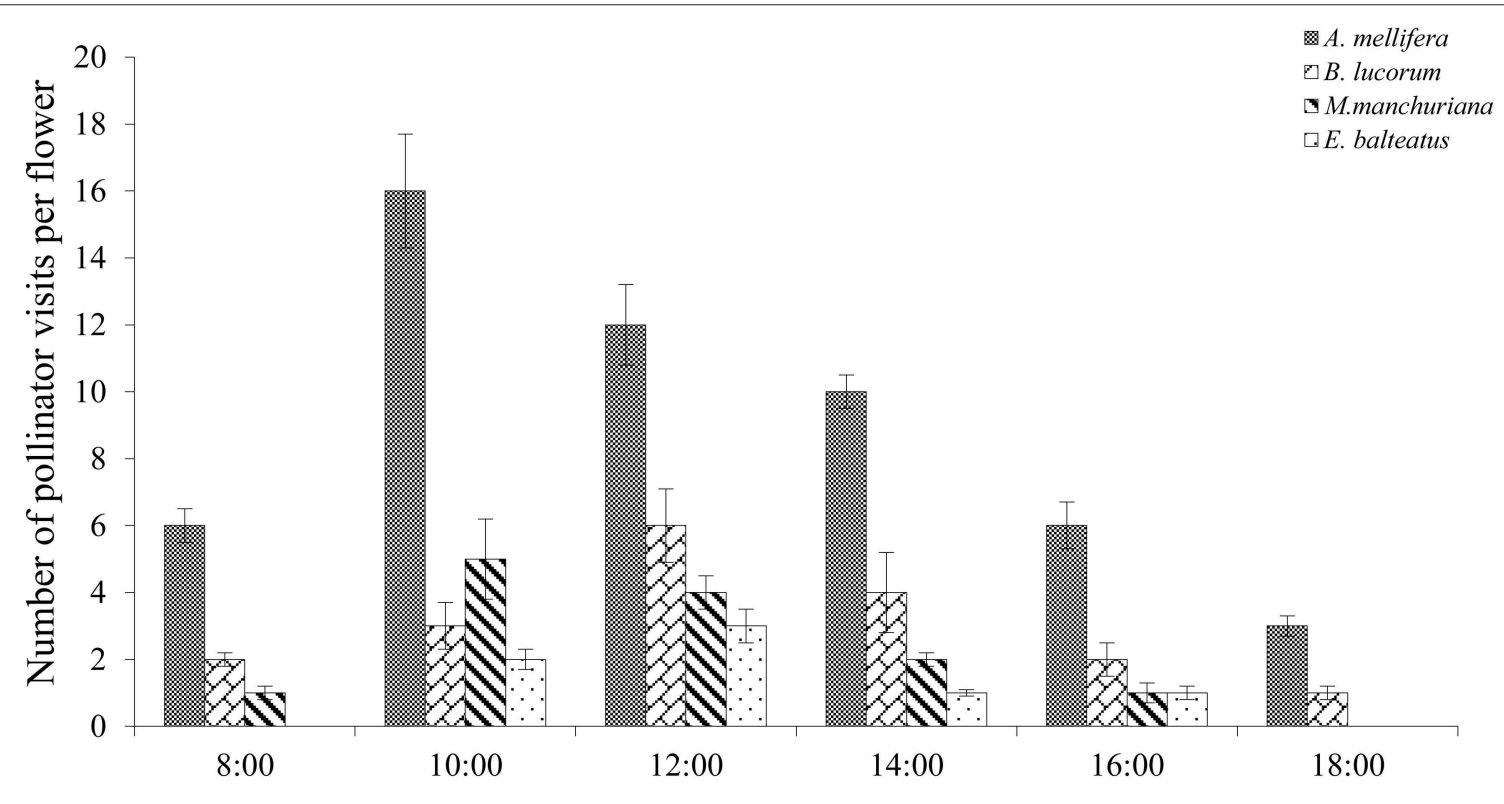

FIGURE 5 | Frequency of dominant pollinator visits to C. microphylla flowers.

as they rarely touched the stigma in their infrequent visitation. Moreover, A. mellifera exhibited effective visits because their hairy bodies can easily deposit more pollen per visit. In $C$. microphylla, our results indicated significant differences in the number of pollinator visits among the pollinator species $(P$ $<0.05)$.

In C. microphylla, the flowers have a tripping mechanism. Pollinator activity starts with flowers in anthesis, and the pollinator also acts as a tripping agent. A. mellifera were the first visitors in the morning, and they pushed the tepals out to enter these flowers. In addition, pollen release peaked between 10:00 and 15:00, and A. mellifera started their activity at 08:00 and finished at 18:00 (Figure 5). The greatest activity of $A$. mellifera overlapped with this peak period of C. microphylla. Our findings demonstrated that there was a significant correlation between the pollinator visitation frequency and the number of open flowers in the grazing ( $r=0.97, P<0.01$; Figure 6$)$ and natural habitats $(r$ $=0.88, P<0.01$; Figure 6). 


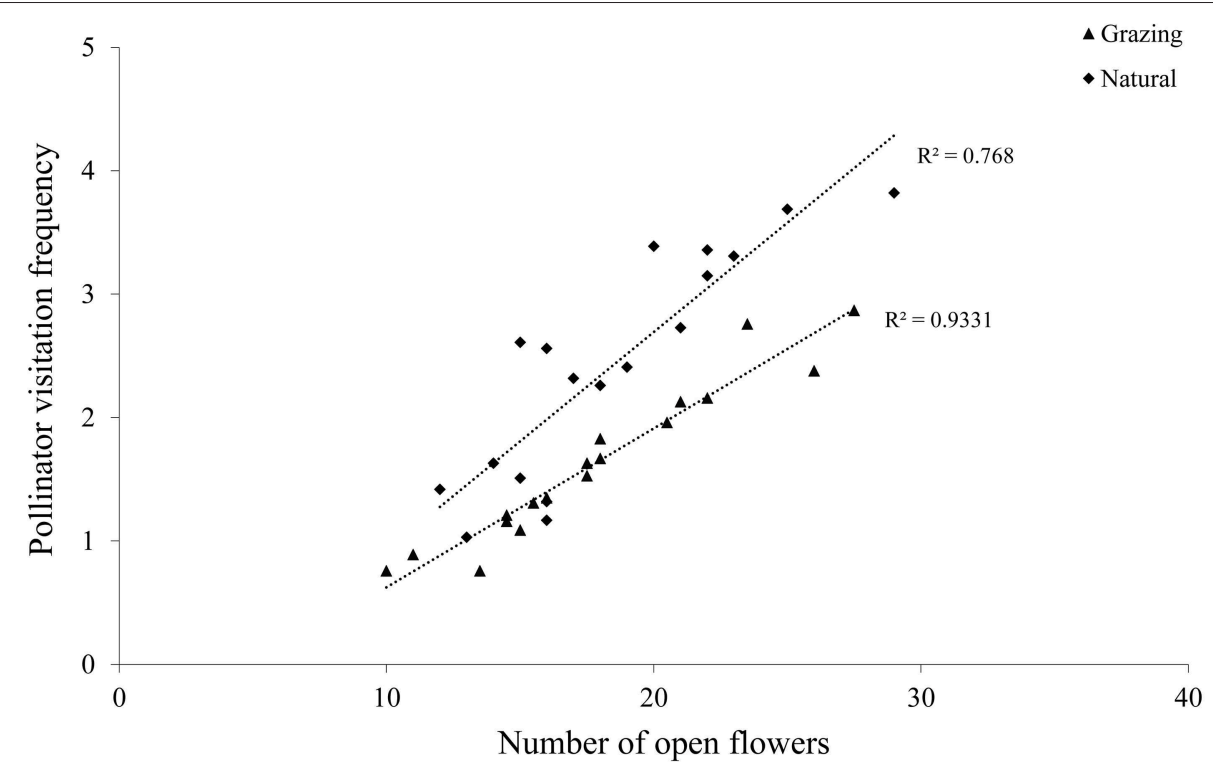

FIGURE 6 | Relationship between the pollinator visitation frequency and the number of open flowers in the studied patches.

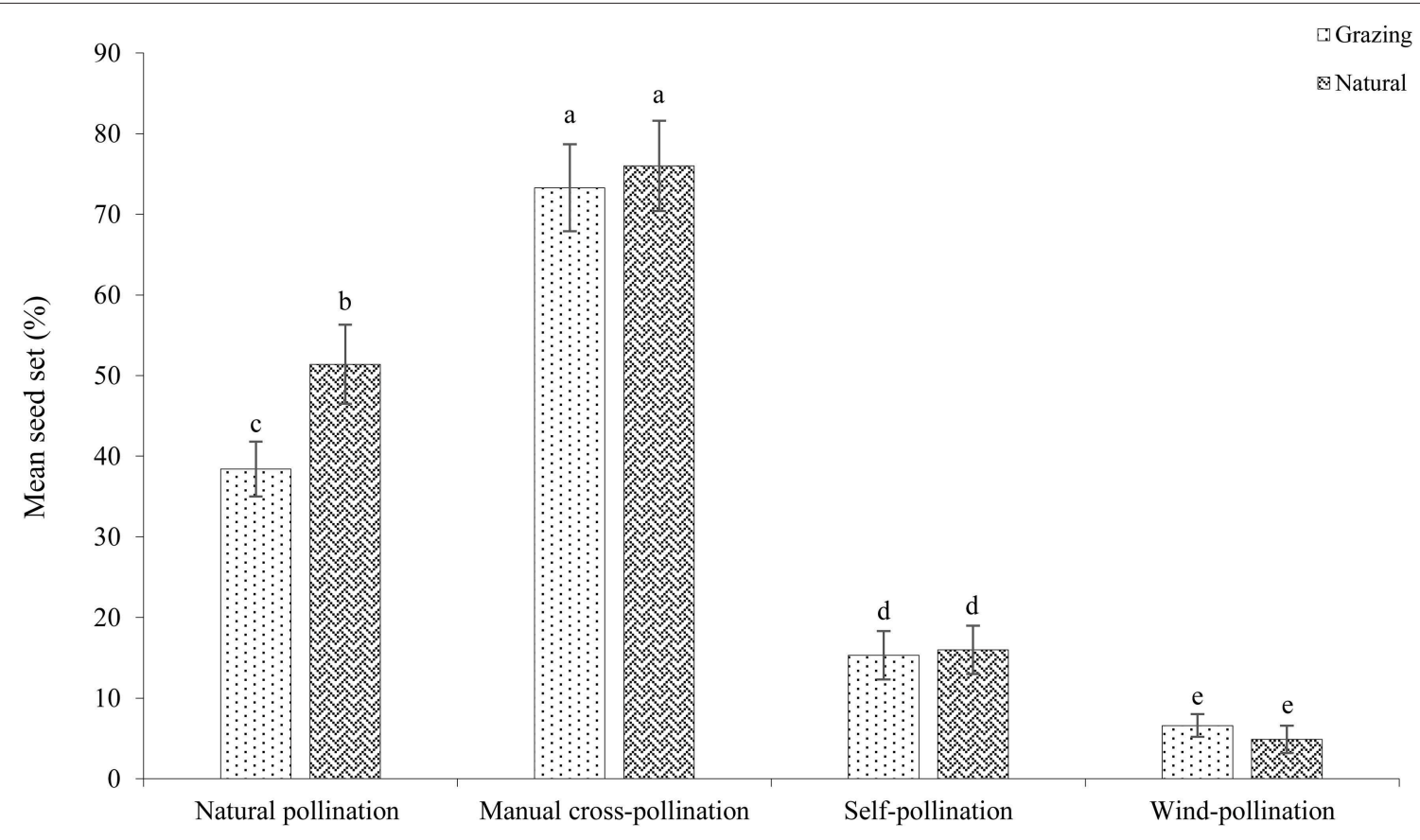

FIGURE 7 | Mean seed set of C. microphylla under different pollination treatments.

\section{Effect of Pollination Experiments on Seed Set}

The mean seed set following each treatment is shown in Figure 7. In both habitats, the mean seed set in the crosspollinated treatment was significantly higher than that in the naturally pollinated treatment (GLM, pollination treatments effect, likelihood ratio $\chi^{2}=97, d f=1, P<0.001$; Table 3), suggesting that outcrossing was dominant in the breeding system. Our findings further demonstrate that there was a significant difference in the seed set between the natural and grazing habitats (GLM, population types effect, likelihood ratio $\chi^{2}=25, d f=1$, $P<0.001)$.

In the natural plants, the seed set of the natural and windpollinated flowers was $51.4 \pm 4.9$ and $4.9 \pm 1.7 \%$, respectively. 
TABLE 3 | Effect of different habitats (grazing and natural), treatments (cross-pollinated and natural pollinated), and years on the seed set of $C$. microphylla.

\begin{tabular}{lccc}
\hline & \multicolumn{3}{c}{ Seed set } \\
\cline { 2 - 4 } & likelihood ratio $\chi^{2}$ & $\boldsymbol{d f}$ & $\boldsymbol{P}$ \\
\hline Habitat types $(\mathrm{H})$ & 25.85 & 1 & $P<0.001$ \\
Treatments $(T)$ & 97.25 & 1 & $P<0.001$ \\
Years $(Y)$ & 0.27 & 1 & $P<0.001$ \\
\hline
\end{tabular}

In addition, our results indicated that the seed set of the self-pollinated flowers was only $12.8 \pm 1.4 \%$. Our findings demonstrated that insect pollination successfully promoted reproductive success. In the plants in the natural plots, the seed set of the self-pollination and manual cross-pollination treatments was $16.0 \pm 3.0$ and $76.0 \pm 5.6 \%$, respectively. The SCI value of C. microphylla was 0.21 , and C. microphylla was selfcompatible. In the natural pollination treatment, the mean seed set significantly differed between the natural and grazing plots (natural, $51.4 \pm 4.9 \%$; grazing, $38.4 \pm 3.4 \%$; $d f=1, P<0.05$ ).

\section{DISCUSSION}

\section{Floral Characters Influence Pollinator Visitation in Different Habitats}

In many flowering plants, pollinators are the major selective agents affecting the floral characters, suggesting that many independent evolutionary adaptations have occurred in the floral characters to match their effective pollinators (Merxem et al., 2009; Chen et al., 2018). In Dactylorhiza lapponica, there is a significant correlation between the strength of pollinator limitation and selection on floral characters, and this study also indicates the importance of plant-insect-environment system (Sletvold and Ågren, 2014). In addition, floral characters and anthers attract pollinators to specific flowers and nectar and pollen are the targets of pollinators (Ortíz et al., 2010). Pollinator abundance, diversity, and activity are declining due to human interference, and harsh environments reduce floral rewards and resources (Jennersten, 1988; Michael et al., 2003; Amparo et al., 2015). Grazing and habitat changes can affect pollinator visitation, which influences the success of effective pollination and could further alter the outcrossing success and seed production of plants (VanDyck and Matthysen, 1999; RodríguezOseguera et al., 2013). This study found that the differences in visiting frequency could be associated with the density of flower resources. In addition, we concluded that pollinator visitation of C. microphylla has pervasive effects on seed set success or failure.

Pollinator activity could be associated with human impacts that affect pollinator visitation and behavior (Rodríguez-Cabal et al., 2007; Chen and Zuo, 2019). The grazing experiments showed that grazing had a significant effect on plant resources in the studied habitats. In addition, trampling by livestock significantly reduces vegetation cover and overgrazing has been considered a significant contributor to grassland degradation
(Li et al., 2011; Chen and Zhao, 2019; Du et al., 2019). In the current study, C. microphylla played an important role in the arid study environment because its root system is efficient in absorbing water (Fang et al., 2011), rendering it drought resistant. In addition, C. microphylla often forms stable communities that play a significant role in sand fixation $(\mathrm{Fu}$, 1993). Natural plants can attract more pollinator visitation than grazing plants because natural plants possess more floral resources than grazing plants (Ortíz et al., 2010). Floral traits and pollinator activity are largely considered to be co-adaptive attributes in which plants allocate resources to attract effective pollinators, and pollinators then evolve traits to better exploit floral resources in different habitats (Gómez et al., 2010). The grazing experiment significantly influenced the floral characters, and the natural plants tended to have more open flowers with large corollas and long spurs. In this study, we found that the grazing habitat could affect the pollination success of $C$. microphylla and reduced pollinator visitation. Therefore, we could increase the natural vegetation and grassland restoration through enclosures and improve the seed set of C. microphylla in fenced-off soil.

\section{Pollinator Limitation Affects Pollination Success}

Pollination is essential for plant life-history, and effective pollinator visitation appears to be a good indicator of pollination activity (Tewksbury et al., 2002). In addition, pollinator limitation affects processes ranging from pollination to seed production (Ryan and David, 2013; Chen and Zhao, 2019). Pollinator limitation studies provide a way to evaluate the reproductive consequences of pollinator services, and different pollination levels of plants may be correlated with differences in the effectiveness of pollinators (Suzuki, 2000). Previous studies have not observed the relationship between pollinator limitation and seed production in the tripping mechanism (Zimmerman and Aide, 1989; Suzuki, 2000). In C. microphylla, the pollinator acts as a tripping agent; thus, effective visits to flowers could be identified. Our results indicated that the percentage of seeds among the visited flowers was significantly positively correlated with the insect visitation rate, showing that pollinator limitation occurred in the plants with low insect visitation rates. In this study, our findings demonstrated that a positive relationship existed between the higher insect visitation rates and higher percentages of seed production and that the seed production of the pollinated flowers in the natural plants was higher than those of flowers in the grazing plants. A similar study has also been documented in calcareous grasslands, indicating that many animal-pollinated species may experience pollinator limitation and affect pollinator-mediated selection for pollination activity (Goverde et al., 2002). Therefore, pollinator efficiency was the dominant limiting factor of seed production in C. microphylla.

\section{Pollinator Activity and Breeding System}

Many studies found a general positive effect of pollinator frequency and effectiveness on pollination success in flowering plants, and this effect is particularly strong in self-incompatible 
plants (Gómez et al., 2007; Rodríguez-Oseguera et al., 2013). The effective visitation frequency of pollinators and delivery of pollen to receptive stigma are the determinants of pollination success (Lennartsson, 2002; Kishore et al., 2012; Chen et al., 2019). Corbett (2003) noted that pollinator visitation and pollen transfer are the main biotic factors influencing pollination success. We found that $A$. mellifera landed on the front of the flower, using its head to drive the flap forward while tripping the flap with its forefoot, and then inserted its proboscis into the base of the petals to obtain pollen and nectar. Therefore, A. mellifera could be treated as an effective pollinator of the studied plant. In this study, compared to other pollinators, $A$. mellifera can collect more pollen and visit more flowers. In addition, A. mellifera is the main raised species in China, and it is mainly distributed in western Inner Mongolia, Gansu, and Huabei. C. microphylla is a nectar species that has a bright color and concentrates during the flowering period (Guan and Ma, 2014), which could attract more visits of A. mellifera (Luo et al., 2019). In most flowering plants, a high frequency of pollinator visits is efficient because the filaments of flowers dry easily in arid regions. In C. microphylla, the complete opening and pollen release of the flowers were observed between 09:00 and 15:00, which represented a significant period for pollination success. Furthermore, A. mellifera activity overlapped with this period.

Most plant species act solely based on a combination of self-pollination and outcrossing mechanisms (Harder and Barrett, 1995; Huang et al., 2006; Chen et al., 2015). Wind pollination also occurs in C. microphylla, but the seed production is low. We found that insect pollination successfully promoted seed production and played a dominant role in the breeding system. Self-pollination has an advantage in seed production when the normal pollinators are missing or reduced in abundance (Huang et al., 2006). Our results indicated that C. microphylla displays self-pollination and outcrossing simultaneously and that self-pollination plays an assisting role in ensuring successful pollination.

\section{REFERENCES}

Alberto, L. T., and Fernando, V. (2014). Pollinator-mediated phenotypic selection does not always modulate flower size and number in the large-flowered Mediterranean shrub Cistus ladanifer (cistaceae). Bot. J. Linn. Soc. 176, 540-555. doi: 10.1111/boj. 12217

Allen-Wardell, G., Bernhardt, P., Bitner, R., Burquez, A., Buchmann, S., Cane, J., et al. (1998). The potential consequences of pollinator declines on the conservation of biodiversity and stability of food crop yields. Conserv. Biol. 12, 8-17. doi: 10.1046/j.1523-1739.1998. 97154.x

Amparo, L., Rebekka, L., and Ørjan, T. (2015). Pollen limitation, species' floral traits and pollinator visitation: different relationships in contrasting communities. Oikos 124, 174-186. doi: 10.1111/oik. 01525

Ashman, T. L., Knight, T. M., Steets, J. A., Amarasekare, P., Burd, M., Campbell, D. R., et al. (2004). Pollen limitation of plant reproduction: ecological and evolutionary causes and consequences. Ecology 85, 2408-2421. doi: 10.1890/03-8024

\section{CONCLUSIONS}

In our study, pollinator limitation was determined to be the dominant factor limiting seed production. The floral characters were moderately positively correlated, and there were more open flowers with large corollas and long spurs in the natural plants than the grazing plants. In addition, the number of open flowers and rate of pollinator visitation were positively correlated. We found that the floral characters and pollinator limitation affected the pollination success of C. microphylla in different habitats.

\section{DATA AVAILABILITY STATEMENT}

All datasets generated for this study are included in the article/supplementary material.

\section{AUTHOR CONTRIBUTIONS}

MC designed the experiment and wrote the manuscript. XZh and $\mathrm{XZu}$ provided editorial advice.

\section{FUNDING}

This research work was supported by China National Key Research and Development Plan (2016YFC0500506), National basic resource survey on the desert major plant communities in China (2017FY100200), National Natural Science Foundation of China (31600252), and CAS Light of West China Program (Y729821001; Y829921001), National Nature Science Foundation of China $(41771117 ; 41877540)$.

\section{ACKNOWLEDGMENTS}

We would like to thank Urat Desert-grassland Research Station and Naiman Desertification Research Station for all the help and support during this study. We also wish to express our appreciation to the reviewers for valuable comments on the manuscript.
Ashman, T. L., and Morgan, M. T. (2004). Explaining phenotypic selection on plant attractive characters: male function, gender balance or ecological context? Proc. R. Soc. Lond. B 271, 553-559. doi: 10.1098/rspb.2003.2642

Asikainen, E., and Mutikainen, P.(2005). Pollen and resource limitation in a gynodioecious species. Am. J. Bot. 92, 487-494. doi: 10.3732/ajb.92.3.487

Beattie, A. J. (1971). Technique for study of insect-borne pollen. Pan Pac. Entomol. 47:82.

Bierzychudek, P. (1981). Pollinator limitation of plant reproductive effort. Am. Nat. 117, 838-840. doi: 10.1086/283773

Burd, M. (1994). Bateman's principle and plant reproduction, the role of pollen limitation in fruit and seed set. Bot. Rev. 60, 83-139. doi: 10.1007/BF02856594

Chen, M., and Zhao, X. Y. (2017). Effect of pollen and resource limitation on reproduction of Zygophyllum xanthoxylum in fragmented habitats. Ecol. Evol. 7, 9076-9084. doi: 10.1002/ece3.3465

Chen, M., Zhao, X. Y., and Zuo, X. A. (2015). Comparative reproductive biology of Apocynum venetum L. in wild and managed populations in the arid region of NW China. Plant. Syst. Evol. 301, 1735-1745. doi: 10.1007/s00606-014-1192-8

Chen, M., Zhao, X. Y., and Zuo, X. A. (2018). Pollinator activity and pollination success of Medicago sativa L. in a natural and a managed population. Ecol. Evol. 8, 9007-9016. doi: 10.1002/ece3.4256 
Chen, M., Zhao, X. Y., and Zuo, X. A. (2019). Comparative pollen limitation and pollinator activity of Caragana korshinskii kom in natural and fragmented habitats. Sci. Total Environ. 654, 1056-1063. doi: 10.1016/j.scitotenv.2018.11.148

Chen, M., and Zhao, X. Z. (2019). Impact of floral characters, pollen limitation, and pollinator visitation on pollination success in different populations of Caragana korshinskii Kom. Sci. Rep. 9:9741. doi: 10.1038/s41598-019-46271-Z

Chen, M., and Zuo, X. A. (2019). Effect of pollen limitation and pollinator visitation on pollination success of Haloxylon ammodendron (C. A. Mey.) bunge in fragmented habitats. Front. Plant. Sci. 10:327. doi: $10.3389 /$ fpls.2019.00327

Corbett, S. A. (2003). Nectar sugar content: estimating standing crop and secretion rate in the field. Apidologie 34, 1-10. doi: 10.1051/apido:2002049

Cresswell, J. E. (1997). Spatial heterogeneity, pollinator behaviour and pollinatormediated gene flow: bumblebee movements in variously aggregated rows of oil-seed rape. Oikos 78, 546-556. doi: 10.2307/3545616

Du, H. Q., Zuo, X. A., Li, S., Wang, T., and Xue, X. (2019). Wind erosion changes induced by different grazing intensities in the desert steppe, Northern China. Agric. Ecosyst. Environ. 274, 1-13. doi: 10.1016/j.agee.2019.01.001

Fang, X. W., Li, F. M., Zhang, H. N., and Jiang, Z. R. (2011). The comparation of drought resistance between Caragana species (Caragana arborescens, $C$. korshinskii, C. microphylla) and two chickpea (Cicer arietinum L.) cultivars. Acta. Ecol. Sin. 31, 2437-2443. doi: 10.3969/j.issn.1000-0933

Fu, K. J. (1993). Flora of China. Beijing: Science Press.

Gómez, J. M., Abdelaziz, M., Lorite, J., Munõz-Pajares, A. J., and Perfectti, F. (2010). Changes in pollinator fauna cause spatial variation in pollen limitation. J. Ecol. 98, 1243-1252. doi: 10.1111/j.1365-2745.2010.01691.x

Gómez, J. M., Bosch, J., Perfectti, F., Fernández, J., and Abdelaziz, M. (2007). Pollinator diversity affects plant reproduction and recruitment: the tradeoffs of generalization. Oecologia 153, 597-605. doi: 10.1007/s00442-0070758-3

Goverde, M., Schweizer, K., Baur, B., and Erhardt, A. (2002). Small-scale habitat fragmentation effects on pollinator behaviour: experimental evidence from the bumblebee Bombus veteranus on calcareous grasslands. Biol. Conserv. 104, 293-299. doi: 10.1016/S0006-3207(01)00194-X

Grindeland, J. M., Sletvold, N., and Ims, R. A. (2005). Effects of floral display size and plant density on pollinator visitation rate in a natural population of Digitalis purpurea. Funct. Ecol. 19, 383-390. doi: $10.1111 /$ j.1365-2435.2005.00988.x

Guan, L. J., and Ma, C. C. (2014). The research progress of Caragana species during the 21st century. Acta Agrestia. Sin. 22, 697-705.

Hadley, A. S., and Betts, M. G. (2012). The effects of landscape fragmentation on pollination dynamics: absence of evidence not evidence of absence. Biol. Rev. 87, 526-544. doi: 10.1111/j.1469-185X.2011.0 0205.x

Harder, L. D., and Barrett, S. C. H. (1995). Mating cost of large floral displays in hermaphrodite plants. Nature 373, 512-515. doi: 10.1038/373512a0

Huang, Y., Zhang, C. Q., Blackmore, S., Li, D. Z., and Wu, Z. K. (2006). A preliminary study on pollination biology of Omphalogramma souliei Franch. (primulaceae), a species endemic to China. Plant. Syst. Evol. 261, 89-98. doi: 10.1007/s00606-006-0430-0

Jennersten, O. (1988). Pollination in Dianthus deltoides (caryophyllaceae): effects of habitat fragmentation on visitation and seed set. Conserv. Biol. 2, 359-366. doi: 10.1111/j.1523-1739.1988.tb00200.x

Johnson, S. D., and Nilsson, L. A. (1999). Pollen carryover, geitonogamy, and the evolution of deceptive pollination systems in orchids. Ecology 80, 2607-2619. doi: 10.1890/0012-9658(1999)0802607:PCGATE2.0.CO;2

Johnson, S. D., and Steiner, K. E. (1997). Long-tongued fly pollination and evolution of floral spur length in the Disa draconis complex (orchidaceae). Evolution 51, 45-53. doi: 10.1111/j.1558-5646.1997.tb02387.x

Johnson, S. D., and Steiner, K. E. (2000). Generalization versus specialization in plant pollination systems. Trends. Ecol. Evol. 15, 140-143. doi: 10.1016/S0169-5347(99)01811-X

Kevan, P. G., Clark, E. A., and Thomas, V. G. (1990). Insect pollination and sustainable agriculture. Am. J. Altern. Agric. 5, 12-22. doi: 10.1017/S0889189300003179

Kishore, K., Shukla, A. K., Babu, N., Sarangi, D. N., and Patanayak, S. (2012). Pollination biology of Annona squamosa L. (annonaceae): evidence for pollination syndrome. Sci. Hortic. 144, 212-217. doi: 10.1016/j.scienta.2012.07.004

Krishnana, S., Kushalappa, C. G., Shaanker, R. U., and Ghazoul, J. (2012). Status of pollinators and their efficiency in coffee fruit set in a fragmented landscape mosaic in South India. Basic Appl. Ecol. 13, 277-285. doi: 10.1016/j.baae.2012.03.007

Lennartsson, T. (2002). Extinction thresholds and disrupted plant-pollinator interactions in fragmented plant populations. Ecology 83, 3060-3072. doi: 10.1890/0012-9658(2002)0833060:ETADPP2.0.CO;2

Li, Y. Q., Zhao, H. L., Zhao, X. Y., Zhang, T. H., Li, Y. L., and Cui, J. Y. (2011). Effects of grazing and livestock exclusion on soil physical and chemical properties in desertified sandy grassland, Inner Mongolia, Northern China. Environ. Earth Sci. 63, 771-783. doi: 10.1007/s12665-010-0748-3

Luo, W. H., Ji, C. H., Liu, J. L., Cao, L., Wang, R. S., Cheng, S., et al. (2019). Study on foraging behavior and effect of pollinators by different bees on Citrus maxima (burm) Merr. Cv. Huangsha Yu. Southwest Chin. J. Agric. Sci. 6, 1360-1365. doi: 10.16213/j.cnki.scjas.2019.6.025

Melissa, F., Linley, K., Jesson, K., Bobiwash, and Daniel, J. S. (2015). Mitigation of pollen limitation in the lowbush blueberry agroecosystem: effect of augmenting natural pollinators. Ecosphere 6, 1-19. doi: 10.1890/ES15-00148.1

Merxem, D. G., Borremans, B., Jäger, M. L., Johnson, T., Jooste, M., and Ros, P., et al. (2009). The importance of flower visitors not predicted by floral syndromes. S. Afr. J. Bot. 4, 660-667. doi: 10.1016/j.sajb.2009.08.002

Michael, A. W., Margaret, T. E., and Robert, S. B. (2003). Conservation impact of climatic variability on pollination of the federally endangered plant, Clematis socialis (ranunculaceae). Southeast Nat. 2, 11-24. doi: 10.1656/1528-7092(2003)002[0011:CIOCVO]2.0.CO;2

Nayak, K. G., and Davidar, P. (2010). Pollinator limitation and the effect of breeding systems on plant reproduction in forest fragments. Acta Oecol. 36, 191-196. doi: 10.1016/j.actao.2009.12.004

Ortíz, F. E., Stoner, K., Pérez-Negrón, E., and Casas, A. (2010). Pollination biology of Myrtillocactus schenckii (cactaceae) in wild and managed populations of the Tehuacán Valley, México. J. Arid Environ. 74, 897-904. doi: 10.1016/j.jaridenv.2010.01.009

Robertson, A. W., Kelly, D., Ladley, J. J., and Sparrow, A. D. (1999). Effects of pollinator loss on endemic New Zealand Mistletoes (loranthaceae). Conserv. Biol. 13, 499-508. doi: 10.1046/j.1523-1739.1999.97471.x

Rodríguez-Cabal, M. A., Aizen, M. A., and Novaro, A. J. (2007). Habitat fragmentation disrupts a plant-disperser mutualism in the temperate forest of South America. Biol. Conserv. 139, 195-202. doi: 10.1016/j.biocon.2007.06.014

Rodríguez-Oseguera, A. G., Casas, A., Herrerías-Diego, Y., and Pérez-Negrón, E. (2013). Effect of habitat disturbance on pollination biology of the columnar cactus Stenocereus quevedonis at landscape-level in central Mexico. Plant Biol. 15, 573-582. doi: 10.1111/j.1438-8677.2012.00657.x

Ryan, D. B. R., and David, A. M. (2013). Resource reallocation does not influence estimates of pollen limitation or reproductive assurance in Clarkia Xantiana Subsp. Parviflora (onagraceae). Am. J. Bot. 100, 1916-1921. doi: 10.3732/ajb.1300050

Sletvold, N., and Ågren, J. (2014). There is more to pollinator-mediated selection than pollen limitation. Evolution 6, 1907-1918. doi: 10.1111/evo.12405

Sletvold, N., Grindeland, J. M., and Ågren, J. (2010). Pollinator-mediated selection on floral display, spur length and flowering phenology in the deceptive orchid Dactylorhiza lapponica. New Phytol. 188, 385-392. doi: 10.1111/j.1469-8137.2010.03296.x

Stebbins, G. L. (1970). Adaptive radiation of reproductive characteristics in angiosperms. I. Pollination mechanisms. Annu. Rev. Ecol. Syst. 1, 307-326. doi: 10.1146/annurev.es.01.110170.001515

Sun, H. Q., Cheng, J., Zhang, F. M., Luo, Y. B., and Ge, S. (2009). Reproductive success of non-rewarding Cypripedium japonicum benefits from low spatial dispersion pattern and asynchronous flowering. Ann. Bot. Lond. 103, 1227-1237. doi: 10.1093/aob/mcp066

Suzuki, N. (2000). Pollinator limitation and resource limitation of seed production in the Scotch broom, Cytisus scoparius (leguminosae). Plant Spec. Biol. 15, 187-193. doi: 10.1046/j.1442-1984.2000.00038.x

Tewksbury, J. J., Levey, D. J., Haddad, N. M., Sargent, S., Orrock, J. L., and Weldon, A., et al. (2002). Corridors affect plants, animals, and their interactions in fragmented landscapes. Proc. Natl. Acad. Sci. U.S.A. 99, 12923-12926. doi: $10.1073 /$ pnas. 202242699 
Toräng, P., Ehrlén, J., and Ågren, J. (2006). Facilitation in an insect-pollinated herb with a floral display dimorphism. Ecology 87, 2113-2117. doi: 10.1890/0012-9658(2006)872113:FIAIHW2. $0 . \mathrm{CO} ; 2$

VanDyck, H., and Matthysen, E. (1999). Habitat fragmentation and insect flight: a changing 'design' in a changing landscape? Trends Ecol. Evol. 14, 172-174. doi: 10.1016/S0169-5347(99)0 $1610-9$

Zapata, T. R., and Arroyo, M. T. K. (1978). Plant reproductive ecology of a secondary deciduous tropical forest in Venezuela. Biotropica 10, 221-230. doi: $10.2307 / 2387907$

Zimmerman, J. K., and Aide, T. M. (1989). Patterns of fruit production in a neotropical orchid: pollinator vs. resource limitation. Am. J. Bot. 76, 67-73. doi: 10.1002/j.1537-2197.1989.tb1 1286.x

Conflict of Interest: The authors declare that the research was conducted in the absence of any commercial or financial relationships that could be construed as a potential conflict of interest.

Copyright $\odot 2020$ Chen, Zuo and Zhao. This is an open-access article distributed under the terms of the Creative Commons Attribution License (CC BY). The use, distribution or reproduction in other forums is permitted, provided the original author(s) and the copyright owner(s) are credited and that the original publication in this journal is cited, in accordance with accepted academic practice. No use, distribution or reproduction is permitted which does not comply with these terms. 